\title{
Upgrading Human Brain to Blue Brain
}

\section{Shruti Ganji* and Kamala Nayana}

Department of Information Technology (3/4), M.V.S.R Engineering College, Saroornagar Mandal, Nadargul, Hyderabad, Telangana 501510, India

\begin{abstract}
Blue brain is the name given to the world's first virtual brain. That means a machine that can function as human brain. There is an attempt to create an artificial brain that can think, response, take decision, and keep anything in memory. The most important thing is to upload the contents of the normal brain into the computer or virtual brain with help of nanobots.
\end{abstract}

Keywords: Blue; Virtual; Artificial brain; Nanobots

\section{Introduction}

In future, our brains are going to be attacked by the blue brain!! Yeah that's right, but there is nothing to be worried, as it is going to be really useful for us.

As sir Isaac Newton once said that we are like small kids on the sea shore, who are getting curious and excited by finding sea shells and fossils, but beyond the beach there is a huge ocean with diverse creatures and things yet to be discovered. Similarly he wants to say that in the field of technology, there are many things to be invented that might bring a drastic change in the field of science and technology [1].

Human brain is the most valuable creation of god. Intelligence is lost after a person's death .but how can we restore this intelligence? Is there a solution for it? Yes there is and it is called the blue brain technology.

Blue brain is the world's first virtual brain. It is been developed by IBM and within the span of 30 years we will be able to scan ourselves into the computer. The project was initiated and founded by Henry Markram in May 2005 at EPFL (École polytechnique fédérale de Lausanne) (Figure 1).

\section{How to Upload Data into Virtual Brain?}

The uploading is possible by the use of small bots called "Nanobots". They are so small that they can travel through brain and spiral. Its basic functionality is it will monitor activities of neuron and scans the structure of brain. It defines the data using sensory technology (Figure 2).

There is a method called data acquisition where by using nurolucida software package which runs on windows workstation, we reconstruct the Neuronal 3D morphologies by taking the brain slices from the living being. For the Blue brain project a 12 patch clamp instrument was specially developed for it which studies the behaviour of neurons [2].

In simulation, there is software NERON which is written in $\mathrm{C}, \mathrm{C}++$ and FORTRAN where we study the cells using algorithms. These algorithms have to be defined according to age; breed of the living being that is simulated. The software collect data from nanobots is BBP-SDK i.e. Blue Brain Project Software Development Kit. The results are then visualised by RT neuron application written in C++ and openGL (Figure 3).

Using these developments, an experiment was performed using a South American sparrow. A computer model of the bird's lungs was developed. Just as the bird sings forcibly through the folds of tissues, these impulses were transferred to the model which started singing like the bird.

Normal and Virtual Brains differentiation is explained in Figure 4.

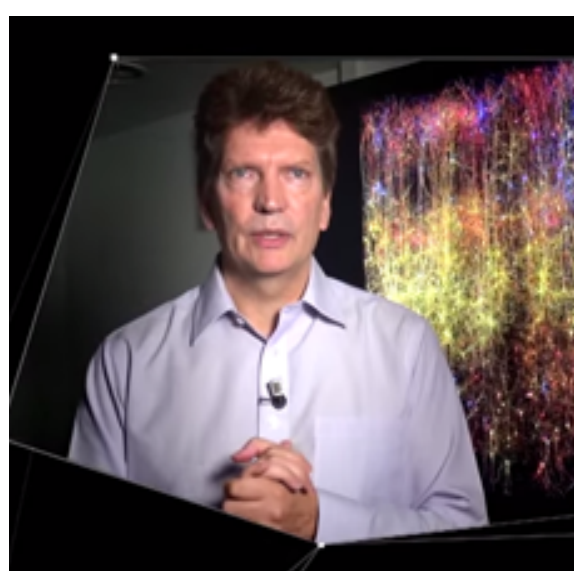

Figure 1: Henry Markram.

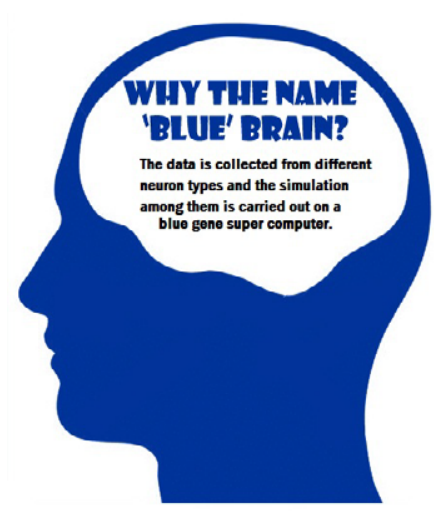

Figure 2: Blue Brain.

*Corresponding author: Shruti Ganji, Department of Information Technology (3/4), M.V.S.R Engineering College. Saroornagar Mandal, Nadargul, Hyderabad, Telangana 501510, India, Tel: 084152-44362; E-mail: shruti25ganji@gmail.com

Received March 28, 2015; Accepted April 04, 2015; Published April 19, 2015

Citation: Ganji S, Nayana K (2015) Upgrading Human Brain to Blue Brain. J Nanomed Nanotechnol 6: 287. doi:10.4172/2157-7439.1000287

Copyright: ( $) 2015$ Ganji S, et al. This is an open-access article distributed under the terms of the Creative Commons Attribution License, which permits unrestricted use, distribution, and reproduction in any medium, provided the original author and source are credited. 


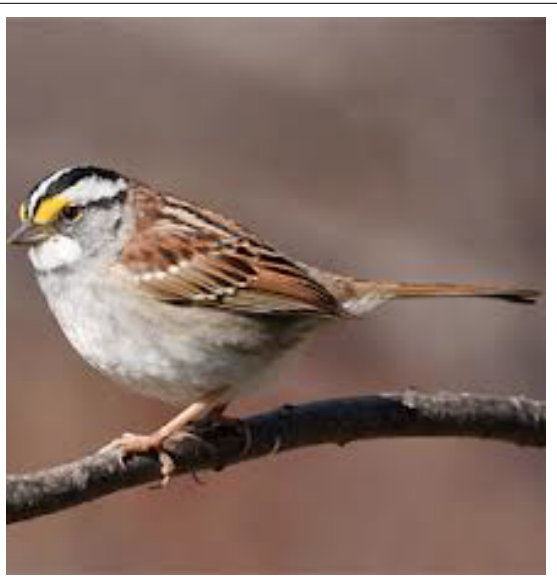

Figure 3: Bird.

\begin{tabular}{|c|c|}
\hline Normal brain & Virtual brain \\
\hline Input through the natural neurons. & $\begin{array}{l}\text { Input through the sillicon chip or artificlal sensory } \\
\text { cells. }\end{array}$ \\
\hline $\begin{array}{l}\text { Interpretation by different states of the neurons in } \\
\text { the brain. }\end{array}$ & Interpretation by a set of bits in the set of register. \\
\hline Output through the natural cells. & Output through the silicon chip. \\
\hline $\begin{array}{l}\text { Processing through arithmetic and logical } \\
\text { calculations. }\end{array}$ & $\begin{array}{l}\text { Processing through arithmetic and logical } \\
\text { calculation and artificial Intelligence. }\end{array}$ \\
\hline $\begin{array}{l}\text { Memory storage through permanent states of } \\
\text { neurons. }\end{array}$ & Memory storage through Secondary memory. \\
\hline
\end{tabular}

Figure 4: Differentiation of Normal and Virtual brains.

\section{Conclusion}

We lose the knowledge of a brain when the body is destroyed after the death. Here blue brain comes in picture. Certain super brains like Bill Gates and Stephen Hawking could be interfaced with computers to make a super computer. Blue brain is an innovative upcoming technology which is an attempt to reverse engineer the human brain and recreate it at the cellular level inside a computer simulation. IT SOUNDS IMPOSSIBLE ISN'T IT? As Christopher Nolan quoted that "perhaps we have just forgotten, that we are still pioneers and we have barely begun". Blue brain project is the step taken to give answers for many unrevealed dark secrets [3].

Blue brain is novel tool for brain disorders. It will be useful to store the intelligent person's brain and use its IQ in research even after his/her death. It can be solution for short term memory and volatile memory at old age and foundation for whole brain simulation. It clears scientific curiosity about consciousness and the human mind. Integration of all neuro scientific research results worldwide. This technology will progress towards building thinking machines (bottom up approach).

As of August 2012 the largest simulations are of mesocircuits containing around 100 cortical columns which are same as that of a honey bee brain. It is hoped that a rat brain neocortical simulation ( 21 million neurons) will be achieved by the end of 2014. If provided with sufficient funding, a full human brain simulation (86 billion neurons) should be possible by 2023 .

\section{References}

1. http://bluebrain.epfl.ch/

2. http://bluebrainfilm.com/bb/

3. http://www.artificialbrains.com/blue-brain-project 